The University of Maine

DigitalCommons@UMaine

Maine-Syracuse Longitudinal Papers

Maine-Syracuse Longitudinal Study

$10-8-2016$

\title{
Habitual chocolate intake and type 2 diabetes mellitus in the Maine-Syracuse Longitudinal Study: (1975-2010): Prospective observations
}

Georgina E. Crichton

Merrill F. Elias

University of Maine - Main, mfelias@maine.edu

Peter J. Dearborn MA

University of Maine, peterdearborn@gmail.com

Michael A. Robbins

University of Maine - Main, robbins@maine.edu

Follow this and additional works at: https://digitalcommons.library.umaine.edu/ longitudinal_papers

Part of the Dietetics and Clinical Nutrition Commons, and the Health Psychology Commons

\section{Repository Citation}

Crichton, Georgina E.; Elias, Merrill F.; Dearborn, Peter J. MA; and Robbins, Michael A., "Habitual chocolate intake and type 2 diabetes mellitus in the Maine-Syracuse Longitudinal Study: (1975-2010): Prospective observations" (2016). Maine-Syracuse Longitudinal Papers. 18.

https://digitalcommons.library.umaine.edu/longitudinal_papers/18 


\title{
Habitual chocolate intake and type 2 diabetes mellitus in the Maine-Syracuse Longitudinal Study: (1975-2010): Prospective observations
}

\author{
Georgina E. Crichton ${ }^{\text {a, }}{ }^{*}$, Merrill F. Elias ${ }^{\text {b, c }}$, Peter Dearborn ${ }^{\text {b }}$, Michael Robbins ${ }^{\text {b, c }}$ \\ ${ }^{a}$ Alliance for Research in Exercise, Nutrition and Activity (ARENA), Sansom Institute for Health Research, University of South Australia, Adelaide, Australia \\ ${ }^{\mathrm{b}}$ Department of Psychology, University of Maine, Orono, ME, USA \\ ${ }^{\mathrm{c}}$ Graduate School of Biomedical Sciences and Engineering, University of Maine, Orono, ME, USA
}

\section{A R T I C L E I N F O}

\section{Article history:}

Received 29 July 2016

Received in revised form

4 October 2016

Accepted 5 October 2016

Available online 8 October 2016

Keywords:

Chocolate

Cocoa

Type 2 diabetes

\begin{abstract}
A B S T R A C T
Compounds in cocoa and chocolate have established cardiovascular benefits, including beneficial effects on insulin resistance, a risk factor for type 2 diabetes mellitus. The aims of this study was to investigate relations between habitual chocolate intakes and diabetes mellitus. Cross-sectional and prospective analyses were undertaken on 953 community-dwelling participants (mean age 62 years, 59\% women) from the Maine-Syracuse Longitudinal Study (MSLS). Habitual chocolate intakes, measured using a food frequency questionnaire, were related to prevalence of diabetes mellitus (cross-sectionally) and with risk of diabetes measured approximately five years later (prospectively). We also examined the relation between diabetes (the predictor) and chocolate consumption (the outcome) up to 30 years later. Chocolate intake was inversely associated with type 2 diabetes. Compared to participants who consumed chocolate more than once per week, those who never or rarely ate chocolate exhibited a significantly higher odds of having type 2 diabetes 5 years later (OR: 1.91, 95\% CI: 1.03, 3.55, p = 0.04), after adjustment for cardiovascular, lifestyle and dietary factors including other polyphenol-rich beverages. However, individuals diagnosed with diabetes prior to the nutritional assessment consumed lower amounts of chocolate at the time of the dietary assessment. Our findings suggest that relations between chocolate and type 2 diabetes may be bi-directional.
\end{abstract}

๑) 2016 Elsevier Ltd. All rights reserved.

\section{Introduction}

Chocolate is a widely consumed food throughout the world, with particularly high intakes in the United States (Statista). With a rich natural complexity, it is commonly associated with pleasure and enjoyment, as well as having a wide-ranging number of medicinal benefits (Macht \& Mueller, 2007; Wilson, 2010). More recent scientific interest has been directed at the cardiovascular benefits derived from chocolate and cocoa consumption (Grassi, Desideri, \& Ferri, 2010; Heiss, Keen, \& Kelm, 2010; Hooper et al., 2012). Flavonoids, naturally occurring polyphenolic compounds present in plant-based foods, represent up to $20 \%$ of the compounds present in cocoa beans (Sokolov, Pavlova, Klosterhalfen, \& Enck, 2013), and may be responsible for the benefits to cardiovascular function (Grassi et al., 2010).

\footnotetext{
* Corresponding author. ARENA, Sansom Institute for Health Research, University of South Australia, GPO Box 2471, Adelaide, South Australia 5001, Australia.

E-mail address: georgina.crichton@unisa.edu.au (G.E. Crichton).
}

Interest in the biological and clinical effects of cocoa flavanols and cocoa-based products such as chocolate is increasing (Grassi et al., 2015; Hooper et al., 2012). To date, there here have been two large epidemiological analyses of the association between long-term chocolate intake and diabetes (Greenberg, 2015; Oba et al., 2010). In the United States, Greenberg (Greenberg, 2015) found an inverse association between frequency of chocolate consumption and diabetes risk over a 13-year follow-up in the prospective Atherosclerosis Risk in Communities Cohort (ARIC). A large analysis of over 13,000 Japanese individuals (Oba et al., 2010) showed a significant inverse association between the consumption of chocolate snacks and risk of diabetes among men, over a 10 -year period. This research is supported by a number of short-term trials demonstrating that ingestion of dark chocolate (Grassi, Lippi, Necozione, Desideri, \& Ferri, 2008, 2005) and cocoa flavanols (Davison, Coates, Buckley, \& Howe, 2008) can improve insulin sensitivity, while a longer term trial has demonstrated that consumption of flavonoid rich chocolate for one year can reduce peripheral insulin resistance in women with type 2 diabetes (Curtis 
et al., 2012).

It may be hypothesised that diabetics however, avoid or limit their intake of high-sugar foods and sugar-sweetened beverages as a result of their diagnosis. Few, if any studies have asked if the association between chocolate intake and diabetes occurs because knowledgeable and treated diabetics limit their chocolate intake. Longitudinal prospective data are necessary to answer this question.

Using data collected from participants in the Maine-Syracuse Longitudinal Study (MSLS), residents of Central New York, USA, the aim of the present study was to determine 1) whether habitual chocolate intakes were associated with diabetes mellitus, with control for cardiovascular, lifestyle and dietary factors; and 2) whether pre-existing diabetes was related to chocolate intake assessed up to 30 years later.

\section{Materials and methods}

\subsection{Participants}

The MSLS was a study of cardiovascular risk factors and cognitive functioning in community living adults (Elias et al., 2009; Robbins, Elias, Elias, \& Budge, 2005). The MSLS consists of five cohorts defined by time of entry into the study (1975-2000). The MSLS employs a time-lagged-longitudinal-cohort design with new subjects featuring an initial wave of data collection and then new subjects recruited into the study every five years with the same recruitment procedures as employed for every wave.

At initial recruitment, participants were living independently in Syracuse, New York or in the adjacent Central New York area. The only exclusions at recruitment were diagnosis of or treatment for psychiatric illness, alcoholism and inability to comprehend English.

The present study utilized data from participants at waves 1 to 5 (1975-2000), 6 (2001-2006) and 7 (2006-2010). Dietary data were collected for the first time at wave 6 . At wave 6 , participants were excluded for the following reasons: missing data on nutritional or health variables $(n=58)$, history of acute stroke $(n=28)$, probable dementia $(n=8)$, undertaking renal dialysis treatment ( $n=5)$, inability to read English $(n=1)$, prior alcohol abuse $(n=1)$, and not participating in the diabetes outcome study $(n=16)$, leaving a sample of 956 study participants. Of these 956 participants with dietary data at wave 6,953 individuals also had diabetes data at waves 1 to 5 . This allowed for a prospective design in which diabetes status at waves 1 to 5 was used to predict chocolate intake at wave 6 , as well as a cross-sectional examination of the relation between chocolate consumption and diabetes status at wave 6 . Of those who participated at wave 6 , the mean time period of participation leading up to wave 6 was $11.3 \pm 7.7$ years.

Eight-hundred twenty-two subjects who provided crosssectional data on chocolate and diabetes (outcome) at wave 6 were invited back to the laboratory for testing at wave 7. Sixhundred nine participants completed data collection. Nineteen participants had incomplete data at wave 7 and were excluded leaving a sample of 590. This allowed for prospective analyses in which chocolate intakes at wave 6 were used to predict diabetes at wave 7 . Mean time between waves 6 and 7 was $4.7 \pm 0.6$ years. The MSLS study design is shown in Fig. 1.

Stroke, defined as a focal neurological deficit of acute onset persisting more than $24 \mathrm{~h}$, was based on self-report and was confirmed by a record review indicating a diagnosis of acute stroke. Clinical diagnoses of dementia were determined from cognitive data and medical records using the National Institute of Neurological and Communicative Diseases and Stroke/Alzheimer's Disease and Related Disorders Association (NINCDS-ADRDA) criteria (McKhann et al., 1984) and confirmed using the ICD-10 Guidelines
(World Health Organization, 1992).

This study was conducted according to the guidelines established by the Declaration of Helsinki and all procedures were approved by the University of Maine Institutional Review Board. Written informed consent was obtained from all subjects.

\subsection{Procedure and assessment}

\subsubsection{Dietary intake}

Dietary intake was assessed using the Nutrition and Health Questionnaire, (Kaaks \& Riboli, 1997; Riboli \& Kaaks, 1997), in which participants were required to stipulate how frequently they consume foods including meat, fish, eggs, breads, cereals, rice and pasta, fruit, vegetables, dairy foods, chocolate, nuts, other snacktype foods, and beverages including alcohol. Participants were required to stipulate how frequently they currently consume each food, from six response options: never, seldom, once/week, 2-4 times/week, 5-6 times/week, and once or more per day. The dietary data was therefore a reflection of nutritional habits at the time of data collection (i.e. at wave 6).

The median score within each response option was used to estimate total intakes per week of the major food groups and total energy; for example, 2-4 times per week was estimated at 3 . The mean number of times each food was consumed on a daily basis was calculated for all foods in the questionnaire. As portion sizes were not stipulated to participants, these totals are an estimate of the number of times each food was consumed. Foods were categorised into one of five major food groups - grains, fruits, vegetables, protein foods, and dairy foods - based on the USDA Food Guide Pyramid (United States Department of Agriculture, 2011). Chocolate intake was categorised into three intake groups: $<1$ serve per week, 1 serve per week, and $>1$ serve per week. Chocolate was not differentiated according to type, i.e. dark, milk, or white chocolate.

\subsubsection{Diabetes assessment}

Standard assay methods were employed (Elias et al., 2006) to obtain fasting plasma glucose $(\mathrm{mg} / \mathrm{dL})$, in addition to total cholesterol (TC, mg/dL), low-density lipoprotein cholesterol (LDL, mg/dL), high-density lipoprotein cholesterol (HDL, mg/dL), triglycerides (mg/dL) and C-reactive protein (CRP, mg/L), following an overnight fast. Diabetes mellitus was defined as fasting glucose level of $\geq 126 \mathrm{mg} / \mathrm{dL}$, being treated with anti-diabetic medication following a medical diagnosis of diabetes.

\subsubsection{Demographics and physical health assessment}

Demographic, socioeconomic and lifestyle characteristics were obtained from the Nutrition and Health Questionnaire (Kaaks \& Riboli, 1997; Riboli \& Kaaks, 1997). Data obtained included smoking history, marital status and medical history. Physical activity was measured with the Nurses' Health Study Activity Questionnaire, a validated measure of time spent engaging in various physical activities (Wolf et al., 1994). Education level was obtained through self-report and ranged from 4 to 20 years.

Body weight was measured with participants wearing light clothing to the nearest $0.1 \mathrm{~kg}$, and height was measured with a vertical ruler to the nearest $0.1 \mathrm{~cm}$. Body mass index (BMI) was calculated as weight in kilograms divided by height in metres squared. Waist circumference (in centimetres) was taken over light clothing, using a non-extendable measuring tape, at the level of the iliac crest. Obesity was defined as BMI $\geq 30 \mathrm{~kg} / \mathrm{m}^{2}$, and cardiovascular disease (CVD) was based upon self-reported history of coronary artery disease, myocardial infarction, congestive heart failure, transient ischemic attack, or angina pectoris, confirmed by medical records. Automated blood pressure (BP) measures (GE DINAMAP 


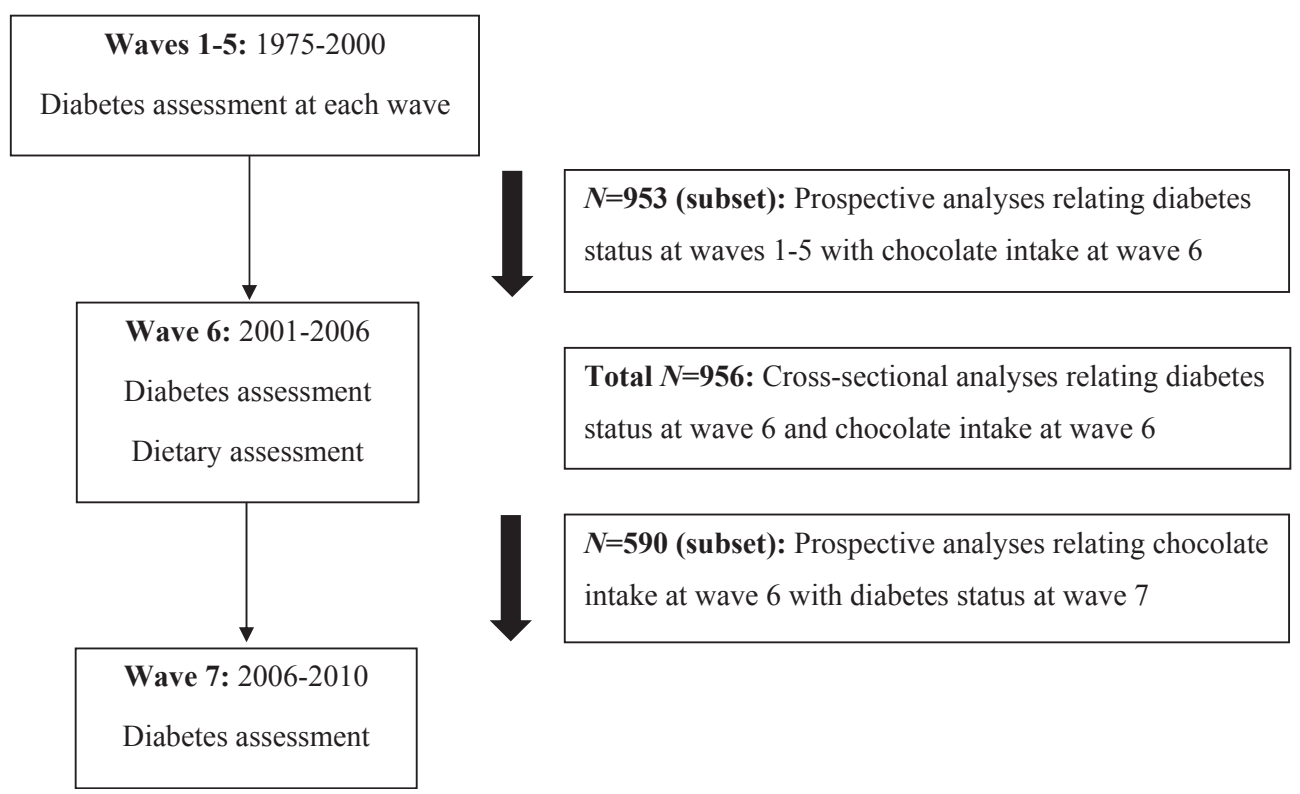

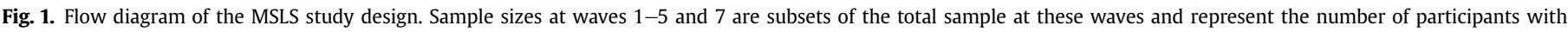
available data at wave 6 also.

100DPC-120XEN, GE Healthcare) were taken in the right arm five times each in recumbent, standing and sitting position after a supine rest for $15 \mathrm{~min}$, and the 15 values were averaged for systolic and diastolic BP. Hypertension was defined as BP of $\geq 140 /$ $90 \mathrm{mmHg}$, or on medication.

\subsection{Statistical analyses}

Participant demographics, health and dietary variables at wave 6 were compared according to diabetes status $(\mathrm{Y} / \mathrm{N})$ at waves 1 to 5 (Table 1) and diabetic status at wave 6 . Independent samples $t$-tests were used for continuous variables and Chi-square for categorical variables for the comparative analyses of demographic, health and dietary variables. Normality of distribution for all health and dietary variables was ascertained by visual inspection of the histograms describing the distribution of scores.

For the cross-sectional and prospective analyses, logistic regression (categorical regression analyses) was used to relate chocolate intakes with the likelihood of having diabetes mellitus. Diabetes status was compared across three chocolate intake categories: $<1$ serve per week, 1 serve per week, and $>1$ serve per week. The highest chocolate intake group served as the reference group. Three covariate models were used to adjust for confounding; these variables were selected based upon correlational analyses (related significantly to chocolate intake and diabetes) or theoretical justification. Other polyphenol-rich foods and beverages (such as tea, coffee, red wine, fruit) were included in the final model if they correlated with either the predictor (chocolate intake) or outcome (diabetes status at wave 6). The following models were employed for all analyses:

Model 1: Basic: age (years) + gender + education (years) + ethnicity;

Extended 1: Basic + total cholesterol $(\mathrm{mg} / \mathrm{dL})$, obesity $(\mathrm{Y} / \mathrm{N})$, hypertension (Y/N), C-reactive protein (CRP; $\mathrm{mg} / \mathrm{L}$ );

Extended 2: adjusted for Basic, Extended $1+$ physical activity (MET-hours/day), total grains (serves/day), coffee (cups/day), red wine (glasses/week).

In our final step, we used general linear modelling to assess whether pre-exiting diabetes (at waves $1-5$ ) predicted chocolate intake between 5 and 30 years later (wave 6).

Except for sensitivity analyses the same covariates were taken from the examination in which chocolate consumption was assessed, wave 6. All statistical analyses were performed with PASW for Windows ${ }^{\circledR}$ version 21.0 software (formerly SPSS Statistics Inc. Chicago, IL, USA); $P<0.05$ was considered statistically significant.

\section{Results}

\subsection{Participant characteristics and chocolate consumption}

Table 1 shows the demographic, health-related variables, and dietary intakes for MSLS participants $(N=953)$ at wave 6 , according to diabetes status at waves 1 to $5(\mathrm{Y} / \mathrm{N})$. Those with diabetes had significantly higher BMI, glucose levels, systolic blood pressure and CRP, but lower total cholesterol than those without diabetes. A significantly higher proportion of diabetics were obese, had CVD and hypertension, compared with non-diabetics. Diabetics consumed more grains and diet soft drinks, but less chocolate, sweets and alcohol than non-diabetics. A comparison of diabetics and non-diabetics at wave 6 showed the same differences in terms of health characteristics and dietary habits.

\subsection{Chocolate consumption and diabetes in the MSLS: cross- sectional and prospective}

Chocolate intake was inversely associated with type 2 diabetes (Table 2). Cross-sectionally, the prevalence of type 2 diabetes was over twice as high in those who consumed chocolate less than once per week compared to those who ate chocolate more than once per week (OR: 2.15, 95\% CI: 1.27, 3.67, $p=0.005$; extended 2 model), with full adjustment for cardiovascular risk factors, obesity, physical activity and other dietary factors, including red wine and coffee.

Prospectively, individuals who consumed chocolate never or rarely had nearly double the risk of having type 2 diabetes approximately 5 years later (OR: $1.91,95 \% \mathrm{CI}: 1.03,3.55, p=0.040$ ), compared to those who ate chocolate more than once per week (with full statistical adjustment). 
Table 1

Demographic, health and nutritional factors at wave 6 , according to diabetes status at waves $1-5$, in the MSLS sample ( $N=953$ ).

\begin{tabular}{|c|c|c|c|c|c|}
\hline \multirow[t]{3}{*}{ Variable (at wave 6) } & \multicolumn{5}{|c|}{ Diabetes $^{\text {a }}$ status (at waves $1-5$ ) } \\
\hline & \multicolumn{2}{|c|}{ No $(n=908,95.3 \%)$} & \multicolumn{2}{|c|}{ Yes $(n=45,4.6 \%)$} & \multirow[t]{2}{*}{$p$-value ${ }^{*}$} \\
\hline & Mean & SD & Mean & SD & \\
\hline Age, years & 62.1 & 12.7 & 66.0 & 10.7 & 0.042 \\
\hline Education, years & 14.8 & 2.7 & 13.3 & 2.3 & $<0.001$ \\
\hline Smoking, cigarettes/day & 1.3 & 5.3 & 0.3 & 2.2 & 0.2 \\
\hline Body mass index, $\mathrm{kg} / \mathrm{m}^{2}$ & 29.1 & 5.6 & 32.8 & 9.2 & $<0.001$ \\
\hline Physical activity, MET-hrs/week & 21.0 & 28.0 & 13.0 & 18.8 & 0.06 \\
\hline Total cholesterol, mg/dL & 203 & 39.6 & 179 & 32.4 & $<0.001$ \\
\hline HDL cholesterol, mg/dL & 53.9 & 15.5 & 46.6 & 11.8 & 0.002 \\
\hline LDL cholesterol, mg/dL & 122 & 33.3 & 103 & 29.5 & $<0.001$ \\
\hline Systolic blood pressure, mm Hg & 130 & 21.5 & 140 & 23.8 & 0.004 \\
\hline Diastolic blood pressure, $\mathrm{mm} \mathrm{Hg}$ & 70.4 & 10.1 & 69.8 & 9.1 & 0.7 \\
\hline Fasting blood glucose, $\mathrm{mg} / \mathrm{dL}$ & 96.6 & 23.5 & 147 & 59.0 & $<0.001$ \\
\hline Triglycerides, mg/dL & $\begin{array}{l}143 \\
\text { (median 115) }\end{array}$ & 114 & $\begin{array}{l}148 \\
\text { (median 127) }\end{array}$ & 76.9 & 0.8 \\
\hline C-reactive protein, $\mathrm{mg} / \mathrm{L}$ & $\begin{array}{l}0.41 \\
\text { (median } 0.25 \text { ) }\end{array}$ & 0.47 & $\begin{array}{l}0.61 \\
\text { (median } 0.34 \text { ) }\end{array}$ & 0.62 & 0.006 \\
\hline \multicolumn{6}{|l|}{ Dietary variables } \\
\hline Chocolate intake, times/week & 2.0 & 1.8 & 1.2 & 1.5 & 0.009 \\
\hline Total grains, serves/day & 3.7 & 2.0 & 4.4 & 2.4 & 0.036 \\
\hline Total meats, serves/day & 2.0 & 0.9 & 2.3 & 0.9 & 0.1 \\
\hline Total fruit, serves/day & 1.6 & 1.0 & 1.7 & 1.0 & 0.5 \\
\hline Total vegetables, serves/day & 2.8 & 1.1 & 2.5 & 1.0 & 0.1 \\
\hline Total dairy foods, serves/day & 2.0 & 1.1 & 2.1 & 1.1 & 0.5 \\
\hline Total sweets, serves/day & 2.5 & 2.2 & 1.6 & 1.4 & 0.004 \\
\hline Regular soft drinks, glasses/day & 0.4 & 1.1 & 0.3 & 0.5 & 0.5 \\
\hline Diet soft drinks, glasses/day & 0.5 & 1.2 & 1.2 & 1.9 & $<0.001$ \\
\hline Alcohol, g/week & 37.8 & 71.3 & 11.8 & 29.7 & 0.015 \\
\hline \multirow[t]{2}{*}{ Total intake, total serves/day all food groups } & 14.8 & 4.6 & 14.6 & 4.5 & 0.8 \\
\hline & $n$ & $\%$ & $n$ & $\%$ & $p$-values* \\
\hline Gender & & & & & 0.2 \\
\hline Males & 367 & 40.4 & 23 & 51.1 & \\
\hline Females & 541 & 59.6 & 22 & 48.9 & \\
\hline Ethnicity & & & & & 0.037 \\
\hline African American & 52 & 5.7 & 6 & 13.3 & \\
\hline Other & 856 & 94.3 & 39 & 86.7 & \\
\hline Obesity $^{\mathrm{c}}$ at wave 6 & 322 & 37.2 & 25 & 56.8 & 0.009 \\
\hline $\mathrm{CVD}^{\mathrm{b}}$ at wave 6 & 123 & 13.5 & 15 & 33.3 & $<0.001$ \\
\hline Hypertension $^{\mathrm{d}}$ & 550 & 60.6 & 39 & 86.7 & $<0.001$ \\
\hline
\end{tabular}

Abbreviations: CVD, cardiovascular disease; HDL, high-density lipoprotein; LDL, low-density lipoprotein; MET, metabolic equivalent.

${ }^{*} P$-values were obtained by analysis of variance for continuous variables or the chi-square test for categorical variables.

a Diabetes mellitus defined as fasting glucose level of $\geq 126 \mathrm{mg} / \mathrm{dL}$, or being treated with anti-diabetic medication.

b CVD based upon self-reported history of coronary artery disease, myocardial infarction, congestive heart failure, transient ischemic attack, or angina pectoris, confirmed by medical records.

c Obesity defined as BMI $\geq 30 \mathrm{~kg} / \mathrm{m}^{2}$.

${ }^{\mathrm{d}}$ Hypertension defined as $\mathrm{BP} \geq 140 / 90 \mathrm{mmHg}$ or being treated with anti-hypertensive medication.

\subsection{Chocolate consumption and incident diabetes}

The odds ratios associated with incident diabetes (new cases at wave 7 compared to wave 6) were not significantly different as a function of level of chocolate consumption (all $p$ values $>0.05$ ). Mean chocolate intakes were slightly lower amongst those who did develop diabetes $(n=30$; mean chocolate intake $=1.7 \pm 1.9$ serves/ week) compared to those who did not develop diabetes $(n=498$; mean chocolate intake $=2.0 \pm 1.8$ serves/week) in this 5 -year time period $(p=0.4)$. Of those individuals who did develop diabetes between waves 6 and 7, 30\% consumed chocolate more than once per week; whilst $41 \%$ of individuals who did not go on to develop diabetes consumed chocolate more than once per week.

\subsection{Pre-existing diabetes and chocolate consumption: prospective}

Nearly $5 \%$ of participants at waves 1 to 5 had type 2 diabetes. As shown in Table 3, those with diabetes at these earlier waves ate significantly less chocolate at wave 6 than those without diabetes.
Statistically adjusting for demographic, health and dietary factors, including physical activity and intakes of coffee and red wine, those without diabetes ate chocolate approximately twice per week; compared to a mean intake of 1.2 serves per week by diabetics (fully extended model, $p=0.009$ ). The same significant difference in mean wave 6 chocolate intakes were observed when we eliminated diabetics at waves 1 to 4 , and performed the analyses comparing non-diabetics with persons who were diagnosed as diabetic at wave 5 (approximately 5 years between waves, data not shown).

\subsection{Test of interactions and sensitivity analyses}

Tests for interactions (multiplicative effects) with age, sex, and BMI were done. In each case the main effect of the risk factor was included in the model with the interaction term and the basic model was employed. Interaction tests were not statistically significant $(p>0.05)$. Replacing obesity $(\mathrm{Y} / \mathrm{N})$ with BMI $\left(\mathrm{kg} / \mathrm{m}^{2}\right)$ and waist circumference in all models did not alter the results, and neither did replacing total cholesterol with HDL- and LDL- 
Table 2

Odds of having diabetes at waves 6 (cross-sectional) and 7 (prospective), according to chocolate intake at wave 6 in the MSLS.

\begin{tabular}{|c|c|c|c|c|c|c|c|}
\hline \multirow[t]{2}{*}{ Model $^{\mathrm{a}}$} & \multirow[t]{2}{*}{ Chocolate intake group } & \multicolumn{3}{|c|}{ Diabetes $^{\mathrm{b}}$ wave $6(N=956)$} & \multicolumn{3}{|c|}{ Diabetes $^{\mathrm{b}}$ wave $7(N=560)$} \\
\hline & & OR & $95 \% \mathrm{CI}$ & $p$ & OR & $95 \% \mathrm{CI}$ & $p$ \\
\hline \multirow[t]{3}{*}{ Basic } & $<1$ serve/week & 1.92 & $1.15,3.20$ & 0.012 & 2.08 & $1.20,3.61$ & 0.010 \\
\hline & 1 serve/week & 1.39 & $0.80,2.44$ & 0.2 & 1.18 & $0.63,2.22$ & 0.6 \\
\hline & $>1$ serve/week & 1.00 & & & 1.00 & & \\
\hline \multirow[t]{3}{*}{ Extended 1} & $<1$ serve/week & 2.01 & $1.17,3.47$ & 0.012 & 1.98 & $1.10,3.57$ & 0.023 \\
\hline & 1 serve/week & 1.25 & $0.68,2.33$ & 0.5 & 1.16 & $0.60,2.27$ & 0.7 \\
\hline & $>1$ serve/week & 1.00 & & & 1.00 & & \\
\hline \multirow[t]{3}{*}{ Extended 2} & $<1$ serve/week & 2.15 & $1.27,3.67$ & 0.005 & 1.91 & $1.03,3.55$ & 0.040 \\
\hline & 1 serve/week & 1.23 & $0.67,2.29$ & 0.5 & 1.27 & $0.64,2.52$ & 0.5 \\
\hline & $>1$ serve/week & 1.00 & & & 1.00 & & \\
\hline
\end{tabular}

Abbreviations: $\mathrm{CI}$, confidence interval; OR, odds ratio.

${ }^{a}$ Basic: adjusted for age, education, sex, ethnicity; Extended 1: adjusted for Basic + total cholesterol (mg/dL), obesity (Y/N), hypertension (Y/N), CRP (mg/L); Extended 2: adjusted for Basic, Extended $1+$ physical activity (MET-hours/day), total grains (serves/day), coffee (cups/day), red wine (glasses/week).

b Diabetes: $>126 \mathrm{mg} / \mathrm{dL}$ or on anti-diabetic medication.

cholesterol. Replacing hypertension with systolic and diastolic BP $(\mathrm{mmHg})$ in the statistical models did not alter the results. The main cross-sectional and prospective results remained unchanged when participants with CVD at wave 6 were excluded.

\section{Discussion}

The present study suggests an inverse association between chocolate consumption and diabetes. The findings indicate that those who consume moderate amounts of chocolate are at lower risk for diabetes mellitus. This was seen in the cross-sectional analysis conducted at wave 6 , and prospectively between waves 6 and 7 , following full adjustment for other polyphenol-rich beverages including coffee and red wine.

Two large epidemiological studies support the notion that consuming a moderate amount of chocolate may reduce the risk of diabetes (Greenberg, 2015; Oba et al., 2010). Data from 7802 ARIC participants showed that compared to individuals who ate $1 \mathrm{oz}$. ( $28 \mathrm{~g}$ ) of chocolate less than once per month, those who ate it at least monthly had significantly reduced risk of being diagnosed with diabetes over 10 years (Greenberg, 2015). The greatest risk reduction of $34 \%$ was observed for those who consumed chocolate 2 to 6 times per week. Consuming chocolate more than once per day did not lower the risk further. This is consistent with the viewpoint that the added fat and calories in chocolate beyond a moderate intake may override the positive effects of the cocoa flavanols in chocolate. As for our study, the type of chocolate consumed (dark/milk/white) was not specified.

In a large Japanese study, Oba et al (Oba et al., 2010). examined the risk of diabetes in relation to the consumption of a number of

\section{Table 3}

Multivariate-adjusted mean and standard error for chocolate intake (times per week) at wave 6 , according to diabetes status $(N=953)$ at waves $1-5$.

\begin{tabular}{lllllll}
\hline \multicolumn{2}{l}{ Diabetes status, waves $1-5$} & & & \\
\hline Model & \multicolumn{2}{l}{ No $(n=908,95.3 \%)$} & & \multicolumn{2}{l}{ Yes $(n=45,4.6 \%)$} & \multirow{2}{*}{$p^{\text {a }}$} \\
\cline { 2 - 3 } & Mean & $95 \%$ CI & & Mean & $95 \%$ CI & \\
\hline Basic $^{\text {b }}$ & 2.00 & $1.85,2.07$ & & 1.34 & $0.80,1.87$ & 0.029 \\
Extended 1 & 1.97 & $1.85,2.10$ & & 1.42 & $0.86,1.97$ & 0.05 \\
Extended 2 & 1.98 & $1.84,2.11$ & & 1.15 & $0.55,1.75$ & 0.009 \\
\hline
\end{tabular}

Values are mean and $95 \%$ confidence interval $(\mathrm{CI})$ for chocolate intake (times per week).

a $p$ for difference between means.

b Basic: adjusted for age, education, sex, ethnicity; Extended 1: adjusted for Basic + total cholesterol $(\mathrm{mg} / \mathrm{dL})$, obesity $(\mathrm{Y} / \mathrm{N})$, hypertension $(\mathrm{Y} / \mathrm{N})$, CRP $(\mathrm{mg} / \mathrm{L})$; Extended 2: adjusted for Basic, Extended $1+$ physical activity (MET-hours/day), total grains (serves/day), coffee (cups/day), red wine (glasses/week). high-caffeine foods and beverages, including coffee, tea and chocolate. A 35\% reduced risk for diabetes was observed in men who consumed chocolate at least once per week, compared to those who ate chocolate never or almost never. Similar associations were implied in women. These two studies, suggest that the greatest risk reduction may be observed amongst moderate chocolate consumers (at least once per week).

Supporting these studies, two thorough, recent reviews of the literature (Grassi et al., 2015; Hooper et al., 2012) suggest that cocoa and chocolate may offer cardiometabolic protection. The positive effects of chocolate are attributed to the cocoa flavanols. Epidemiological and clinical studies have repeatedly shown that highflavonoid foods can improve endothelial function, as assessed by flow mediated dilatation, by elevating NO bioavailability and bioactivity (Grassi et al., 2009, 2010, 2013). Conditions of insulin resistance, such as diabetic states, are usually linked to endothelial dysfunction and decreased NO bioavailability. Our findings remained with the addition of coffee and red wine, which both contain polyphenols (Carluccio et al., 2003; Hecimovic, BelscakCvitanovic, Horzic, \& Komes, 2011).

Larger, longer-term clinical trials to confirm the possible cardiovascular benefits derived from cocoa and chocolate consumption have been recommended (Grassi et al., 2015; Hooper et al., 2012). For example, it is unknown whether the high energy, sugar, and fat content of chocolate may weaken or nullify the benefits of cocoa. More attention needs to be paid to the flavanol concentration, sugar and calorie content of cocoa-based foods such as chocolate (Grassi et al., 2015).

Our findings when we related wave $1-5$ diabetes status to chocolate consumption at wave 6 do raise the possibility that relationships between chocolate and diabetes may, in part, reflect a practice in which diabetics choose to eat less chocolate for health reasons. Those who were diabetic at waves 1 to 5 consumed less chocolate at wave 6 . The chocolate-diabetes relation may be bidirectional. This may be likened to inactivity foreshadowing obesity but obesity being associated with poorer lifestyle habits such as lower levels of physical activity, smoking and drinking more alcohol (Crichton et al., 2014; Goday et al., 2016). At wave 6, the diabetic individuals consumed fewer sweets, less alcohol and more diet soft drinks and grains than non-diabetics; these practices are consistent with limiting chocolate consumption. These practices are also consistent with nutritional recommendations made for diabetics during this period of time (1975-2000). Until only recently, sugar was 'forbidden' for diabetics, with recommendations based on tradition rather than evidence (Wheeler, 2000). Diabetes nutrition recommendations have cycled between greater and lesser amounts of different foods, food groups, and 
macronutrients throughout the history of diabetes nutrition therapy, ranging from starvation treatment in 1915 to evidence-based recommendations made in 2002 (Franz, 2004; Franz et al., 2002, 2003). The most commonly held food belief was that diabetics should avoid added sugars and sweets, and restrict naturally occurring sugars, based on the assumption that sucrose and other sugars would aggravate hyperglycaemia as they are more rapidly digested and absorbed, and cause a greater increase in blood sugar levels than starches (Franz et al., 2003). During the period of time in which waves 1 to 5 were conducted, this was the prevalent belief. Clinical trials have subsequently demonstrated that it is the total amount of carbohydrate consumed that is more important than the source or type, (Franz et al., 2002). Nutrition goals for diabetes are therefore similar to those all individuals should strive for to achieve a balanced and healthy diet, with consideration given to total caloric intake in relation to energy needs (American Diabetes Association, 2008). Our investigation of the literature indicates a number of studies that have not taken this dietary modification possibility into consideration, and in our view, it cannot be ruled out in the absence of clinical trials.

Several limitations of the present study must be acknowledged. Dietary data were only obtained at wave 6 , so we are unable to examine any change in chocolate intakes over time in relation to diabetes status at waves $1-5$. Chocolate intake was self-reported, and therefore subject to inherent reporting error. The dietary questionnaire used did not require the respondent to differentiate between dark, milk or white chocolate. Most clinical trials have used dark chocolate as the source of cocoa flavanols. In 2012, the distribution share of chocolate in the United States by favourite chocolate type was $57 \%$ milk chocolate, $35 \%$ dark chocolate, and $8 \%$ white chocolate (Statista). We can therefore make the assumption that the majority of chocolate consumed in this sample was dark or milk, both containing cocoa flavanols to varying degrees. It is certainly plausible that the findings are driven by those consuming milk or dark chocolate only. We are unable to calculate the actual quantities of chocolate and cocoa associated with diabetes status, due to the nature of the questionnaire. Finally, covariates were used from wave 6 , as not all health variables, such as CVD, were collected at earlier waves, and oral glucose tolerance testing was not performed at any waves of the MSLS.

We were able to statistically control for a number of cardiovascular, lifestyle and dietary variables that may confound the association between habitual chocolate consumption and health outcomes such as diabetes. We were able to examine crosssectional and prospective relations between diet and health. Importantly, we were able to consider whether persons with diabetes consumed less chocolate $4-30$ years later. Moreover there is evidence that they modified aspects of their diet in a way consistent with reduction of intake of sweets as one would expect of diabetic individuals during the time period represented at waves 1-5 (1975-2000).

\section{Conclusions}

Clinical trials are necessary to further explore relations between diabetes and chocolate, with consideration given to type, nutritional content and quantity. Relations may reflect both selfselection away from chocolate and the adverse influence of low chocolate levels on prevalent diabetes. A moderate chocolate intake of several times per week may be related to the reduction of the incidence (new cases) of diabetes mellitus, but it is also possible that those diagnosed with diabetes limit or avoid chocolate. Further studies are necessary to examine the influence of chocolate consumption on diabetes mellitus and behavior around food choices.

\section{Conflict of interest}

The authors have no conflicts of interest to declare.

\section{Acknowledgements}

The Maine Syracuse Longitudinal Study was supported by grants R01HL067358, and R01HL081290 from the National Heart, Lung and Blood Institute, National Institutes of Health (USA), and research grant R01AG03055 from the National Institute on Aging, National Institutes of Health (USA). GEC is supported by a National Health and Medical Research Council (NHMRC) Sidney Sax Research Fellowship (GNT1054567) (Australia). The funding sources had no involvement in the study design, data collection, writing or decision to submit for publication.

\section{References}

American Diabetes Association. (2008). Nutrition recommendations and interventions for diabetes: A position statement of the American diabetes association. Diabetes Care, 31(Suppl 1), S61-S78.

Carluccio, M. A., Siculella, L., Ancora, M. A., et al. (2003). Olive oil and red wine antioxidant polyphenols inhibit endothelial activation: Antiatherogenic properties of Mediterranean diet phytochemicals. Arteriosclerosis, Thrombosis, and Vascular Biology, 23, 622-629.

Crichton, G. E., Elias, M. F., Davey, A., et al. (2014). Cardiovascular health: A crossnational comparison between the Maine Syracuse study (Central New York, USA) and ORISCAV-LUX (Luxembourg). BMC Public Health, 14, 253.

Curtis, P. J., Sampson, M., Potter, J., Dhatariya, K., Kroon, P. A., \& Cassidy, A. (2012) Chronic ingestion of flavan-3-ols and isoflavones improves insulin sensitivity and lipoprotein status and attenuates estimated 10-year CVD risk in medicated postmenopausal women with type 2 diabetes: A 1-year, double-blind, randomized, controlled trial. Diabetes Care, 35, 226-232.

Davison, K., Coates, A. M., Buckley, J. D., \& Howe, P. R. (2008). Effect of cocoa flavanols and exercise on cardiometabolic risk factors in overweight and obese subjects. International Journal of Obesity (London), 32, 1289-1296.

Elias, M. F., Robbins, M. A., Budge, M. M., Abhayaratna, W. P., Dore, G. A., \& Elias, P. K. (2009). Arterial pulse wave velocity and cognition with advancing age. Hypertension, 53, 668-673.

Elias, M. F., Robbins, M. A., Budge, M. M., et al. (2006). Homocysteine, folate, and vitamins B6 and B12 blood levels in relation to cognitive performance: The Maine-Syracuse study. Psychosomatic Medicine, 68, 547-554.

Franz, M. J. (2004). The history of diabetes nutrition therapy: From starvation to evidence-based recommendations. Diabetes Voice, 49, 30-33.

Franz, M. J., Bantle, J. P., Beebe, C. A., et al. (2002). Evidence-based nutrition principles and recommendations for the treatment and prevention of diabetes and related complications. Diabetes Care, 25, 148-198.

Franz, M. J., Warshaw, H., Daly, A. E., Green-Pastors, J., Arnold, M. S., \& Bantle, J (2003). Evolution of diabetes medical nutrition therapy. Postgraduate Medical Journal, 79, 30-35.

Goday, A., Calvo, E., Vazquez, L. A., et al. (2016). Prevalence and clinical characteristics of metabolically healthy obese individuals and other obese/non-obese metabolic phenotypes in a working population: Results from the icaria study BMC Public Health, 16, 248.

Grassi, D., Desideri, G., Croce, G., Tiberti, S., Aggio, A., \& Ferri, C. (2009). Flavonoids, vascular function and cardiovascular protection. Current Pharmaceutical Design, 15, 1072-1084.

Grassi, D., Desideri, G., \& Ferri, C. (2010). Flavonoids: Antioxidants against atherosclerosis. Nutrients, 2, 889-902.

Grassi, D., Desideri, G., \& Ferri, C. (2013). Protective effects of dark chocolate on endothelial function and diabetes. Current Opinion in Clinical Nutrition \& Metabolic Care, 16, 662-668.

Grassi, D., Desideri, G., Mai, F., et al. (2015). Cocoa, glucose tolerance, and insulin signaling: Cardiometabolic protection. Journal of Agricultural and Food Chemistry, 63, 9919-9926.

Grassi, D., Desideri, G., Necozione, S., et al. (2008). Blood pressure is reduced and insulin sensitivity increased in glucose-intolerant, hypertensive subjects after 15 days of consuming high-polyphenol dark chocolate. Journal of Nutrition, 138, 1671-1676.

Grassi, D., Lippi, C., Necozione, S., Desideri, G., \& Ferri, C. (2005). Short-term administration of dark chocolate is followed by a significant increase in insulin sensitivity and a decrease in blood pressure in healthy persons. American Journal of Clinical Nutrition, 81, 611-614.

Greenberg, J. A. (2015). Chocolate intake and diabetes risk. Clinical Nutrition, 34, 129-133.

Hecimovic, I., Belscak-Cvitanovic, A., Horzic, D., \& Komes, D. (2011). Comparative study of polyphenols and caffeine in different coffee varieties affected by the degree of roasting. Food Chemistry, 129, 991-1000.

Heiss, C., Keen, C. L., \& Kelm, M. (2010). Flavanols and cardiovascular disease 
prevention. European Heart Journal, 31, 2583-2592.

Hooper, L., Kay, C, Abdelhamid, A et al, (2012). Effects of chocolate, cocoa, and flavan-3-ols on cardiovascular health: A systematic review and meta-analysis of randomized trials. American Journal of Clinical Nutrition, 95, 740-751.

Kaaks, R., \& Riboli, E. (1997). Validation and calibration of dietary intake measurements in the EPIC project: Methodological considerations. European prospective investigation into Cancer and nutrition. International Journal of Epidemiology, 26(suppl 1), S15-S25.

Macht, M., \& Mueller, J. (2007). Immediate effects of chocolate on experimentally induced mood states. Appetite, 49, 667-674.

McKhann, G., Drachman, D., Folstein, M., Katzman, R., Price, D., \& Stadlan, E. M. (1984). Clinical diagnosis of Alzheimer's disease: Report of the NINCDS-ADRDA work group under the auspices of department of health and human services task force on Alzheimer's disease. Neurology, 34, 939-944.

Oba, S., Nagata, C., Nakamura, K., et al. (2010). Consumption of coffee, green tea, oolong tea, black tea, chocolate snacks and the caffeine content in relation to risk of diabetes in Japanese men and women. British Journal of Nutrition, 103 $453-459$.

Riboli, E., \& Kaaks, R. (1997). The EPIC project: Rationale and study design. European prospective investigation into Cancer and nutrition. International Journal of
Epidemiology, 26(suppl 1), S6-S14

Robbins, M. A., Elias, M. F. Elias, P. K., \& Budge, M. M. (2005). Blood pressure and cognitive function in an African-American and a Caucasian-American sample: The Maine-Syracuse study. Psychosomatic Medicine, 67, 707-714.

Sokolov, A. N., Pavlova, M. A., Klosterhalfen, S., \& Enck, P. (2013). Chocolate and the brain: Neurobiological impact of cocoa flavanols on cognition and behavior Neuroscience \& Biobehavioral Reviews, 37, 2445-2453.

Statista. Statistics and facts on the chocolate industry. Retrieved 07.12.15, Available from www.statista.com/statistics/238849/global-chocolate-consumption/.

United States Department of Agriculture. (2011). MyPyramid.Gov.

Wheeler, M. L. (2000). Cycles: Diabetes nutrition recommendations- past, present and future. Diabetes Spectrum., 13, 116.

Wilson, P. K. (2010). Centuries of seeking chocolate's medicinal benefits. Lancet, 376 , $158-159$.

Wolf, A. M., Hunter, D. J., Colditz, G. A., et al. (1994). Reproducibility and validity of a self-administered physical-activity quesionnaire. International Journal of Epidemiology, 23, 991-999.

World Health Organization. (1992). The ICD 10 classification of mental and behavioral disorders: Clinical descriptions and diagnostic guidelines. Geneva: World Health Organization. 